\title{
Double anus in an Ixodes scapularis nymph, a medically important tick vector
}

\author{
Vikas Taank ${ }^{1}$, Frank A. Lattanzio ${ }^{2}$, Hameeda Sultana ${ }^{1,3,4}$ and Girish Neelakanta 1,3,4*
}

\begin{abstract}
Background: Ixodes scapularis ticks are medically important arthropod vectors that transmit several pathogens to humans. The observations of morphological abnormalities, including nanism, missing leg, extra leg, and gynandromorphism, have been reported in these ticks. In this study, we report the presence of two anuses in a laboratoryreared I. scapularis nymph.

Results: Larval ticks were allowed to feed on mice and to molt to nymphs. Two anuses were observed in one of the freshly molted nymphs. Stereo and scanning electron microscopy confirmed the presence of two anuses in one nymph within a single anal groove.
\end{abstract}

Conclusions: This report confirms the rare occurrence of double anus in I. scapularis.

Keywords: Abnormalities, Anus, Microinjection, Ixodes scapularis

\section{Background}

Ticks such as Ixodes scapularis are medically important vectors that transmit several pathogens to humans [1, 2]. In nature, these ticks pass through several different developmental stages in their 2-year life cycle [3]. The six-legged larvae take a blood meal and molt into eightlegged nymphs. Nymphs then take a blood meal and molt into either adult male or female ticks. Female ticks take a blood meal, mate with male ticks, and lay eggs. Eggs then hatch into larvae and the life-cycle continues [3]. Ticks undergo several biotic and abiotic stress conditions during their life-cycle, with potential stress factors including, but are not limited to, changes in temperature, humidity, and lack of hosts to feed upon [3].

The first study that reported abnormalities in ticks was published in 1899 [4]. In the years that followed, several studies have reported morphological abnormalities in various hard and soft ticks including, but not limited to,

*Correspondence: gneelaka@utk.edu

${ }^{1}$ Department of Biological Sciences, Old Dominion University, Norfolk, VA, USA

Full list of author information is available at the end of the article species belonging to genera Ixodes, Amblyomma, Hyalomma, Rhipicephalus, Dermacentor, Haemaphysalis, Ornithodoros, and Argas [5-10]. The cause of abnormalities in ticks could be related to injuries in nature, somatic or germinal mutations, environmental factors, and exposure to insecticides and/or other chemicals during the developmental stages [5, 7-10]. It has also been reported that arthropod blood-feeding on exotic hosts could also result in abnormalities in ticks [11]. Abnormalities in ticks have been broadly classified into two categories: (i) local abnormalities, which include splitting of claws, tarsus, and femur, fusion of appendages, the absence of one or more legs, and defects in mouth parts; and (ii) general abnormalities, which include gigantism, gynandromorphism, nanism, double monsters, and asymmetry of the idiosoma [6].

The observations of local or general abnormalities in ticks are very rare, with the prevalence ranging from 0.028 to $0.2 \%$ in tick populations [12-14]. Kar et al. [12] reported that out of 18,667 ticks analyzed, only 33 specimens had abnormalities. In another study, Tovornik [14] reported that out of 53,930 ticks analyzed, only 15 specimens had abnormalities. In addition, Larson and

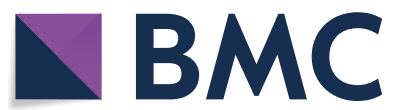

(c) The Author(s) 2021. This article is licensed under a Creative Commons Attribution 4.0 International License, which permits use, sharing, adaptation, distribution and reproduction in any medium or format, as long as you give appropriate credit to the original author(s) and the source, provide a link to the Creative Commons licence, and indicate if changes were made. The images or other third party material in this article are included in the article's Creative Commons licence, unless indicated otherwise in a credit line to the material. If material is not included in the article's Creative Commons licence and your intended use is not permitted by statutory regulation or exceeds the permitted use, you will need to obtain permission directly from the copyright holder. To view a copy of this licence, visit http://creativeco mmons.org/licenses/by/4.0/. The Creative Commons Public Domain Dedication waiver (http://creativecommons.org/publicdomain/ zero/1.0/) applies to the data made available in this article, unless otherwise stated in a credit line to the data. 
Paskewitz [13] reported that out of 8800 nymphs analyzed, only three specimens had major abnormalities. Ixodes scapularis ticks are predominantly found in northeast and upper midwest parts of the USA [3]. Various studies have reported the presence of abnormalities such as nanism, two asymmetrical ticks (one with a missing leg and other with an extra leg), and gynandromorphism in field-collected I. scapularis ticks $[13,15,16]$. A study conducted by the New York State Department of Health and U.S. Department of Agriculture reported that out of more than 81,000 adult I. scapularis analyzed, only two specimens had abnormalities [16]. Collectively, the findings (from studies that analyzed samples of varying sizes) clearly suggest that abnormalities in ticks are very rare.

In this study, we report a local abnormality, namely, the presence of two anuses, in one of the laboratory-reared unfed nymphs. We noted that the two anuses were present within one anal groove. The observation of two anuses in I. scapularis provides further evidence of the presence of rare abnormalities in this group of ticks.

\section{Methods}

Tick colony maintenance and mice

Laboratory-reared I. scapularis ticks (larvae) obtained from a continuously maintained colony at BEI Resources (Manassas, VA, USA))/U.S. Center for Disease Control and Prevention (CDC) were used in this study (CDC catalog no. NR-44115 for larvae of live wild-type I. scapularis). Ixodes scapularis ticks were flagged from vegetation in 2003 in Rhode Island, USA. C3H/HeN mice (female, 4-6 weeks old; Charles River Laboratories, Inc., Wilmington, MA, USA) were used in this study. Larvae were allowed to feed on naïve mice and allowed to molt into nymphs, generating uninfected nymphs. Tick rearing was conducted in an incubator at $23 \pm 2{ }^{\circ} \mathrm{C}$ and $90-95 \%$ relative humidity under a $14 / 10$-h light/dark photoperiod regimen, as described in our previous studies [17-19].

\section{Bacterial isolate, A. phagocytophilum host cell-free dense core isolation, and tick microinjection}

Anaplasma phagocytophilum isolate $\mathrm{NCH}-1$ (obtained from BEI Resources) was used in this study. A host cellfree dense core form of $A$. phagocytophilum (Ap-DC) was isolated from confluent HL-60 cells with $>70 \%$ infection by sonication, followed by multiple differential centrifugation steps as described in previous studies $[19,20]$. To analyze if physical disruption (via microinjection) of the anal pore affects the viability of a tick with double anus, $A p$-DC was introduced by microinjection into the anal pore, as described in our recent study [19]. Microinjected ticks were observed at $2 \mathrm{~h}$ post-microinjection under a stereomicroscope and pictures were taken. Thereafter, the tick with double anus and a normal tick with a single anus were stored in fresh $70 \%$ ethanol in 1.5-ml Eppendorf tube at $4{ }^{\circ} \mathrm{C}$ until other microscopy studies were conducted.

\section{Stereomicroscopic images and video}

To assess the overall health of the live ticks after microinjection, we performed stereomicroscopic visualization. Live ticks were immobilized by placing the ticks (on their dorsal side) on a microscope slide on a double-sided tape. Video and Images were captured using a Nikon SMZ74 $5 \mathrm{~T}$ stereomicroscope (Nikon, Tokyo, Japan) equipped with AmScope CMOS camera attachment (AmScope, Irvine, CA USA) and ToupView Image Capture software 3.7 (AmScope). Image J software (U.S. National Institutes of Health, Bethesda, MD, USA) was used for image enhancements.

\section{Scanning electron microscopy}

To analyze the structural features of the tick with double anus in detail, we studied the tick samples by scanning electron microscopy (SEM). Sample preparation and SEM microscopy were performed at the Virginia Commonwealth University Microscopy Facility (Richmond, VA, USA). Briefly, tick samples were removed from storage in $70 \%$ ethanol and dehydrated through a series of ethanol solutions $(70,80,95$, and 3 changes of $100 \%$ ), following which they were critical point dried using an Autosamdri-814 Critical Point dryer (Tousimis Research Corp., Rockville, MD, USA). The samples were then mounted on standard aluminum SEM mounts and sputter-coated with gold-palladium, using an EMS $550 \times$ sputter coater (Electron Microscopy Sciences, Hatfield, PA, USA). Electron micrographs were captured using a Zeiss EVO 50 XVP scanning electron microscope (Carl Zeiss Microscopy GmbH, Jena, Germany) operating at $10.00 \mathrm{kV}$.

\section{Results and discussion}

Larvae obtained from BEI resources were allowed to feed on naïve $\mathrm{C} 3 \mathrm{H} / \mathrm{HeN}$ mice and the fed larvae were allowed to molt into nymphs. We noted that one of the freshly molted nymphal ticks contained two anuses. SEM images clearly revealed the presence of two anuses in the abnormal nymph (Fig. 1a, b) and only a single anus in the normal nymph (Fig. 1c, d). In addition, the double anuses were found to be in a single anal groove. The abnormal nymph presented a more extensive anal groove with the presence of two anal pores of similar size (Fig. 1a, b). The diameter of both anal pores in the abnormal nymph was between 65 and $67 \mu \mathrm{m}$. The two anuses were separated by approximately $115 \mu \mathrm{m}$, and the largest width of the anal groove was measured to be approximately $315 \mu \mathrm{m}$. In comparision, the single anal 

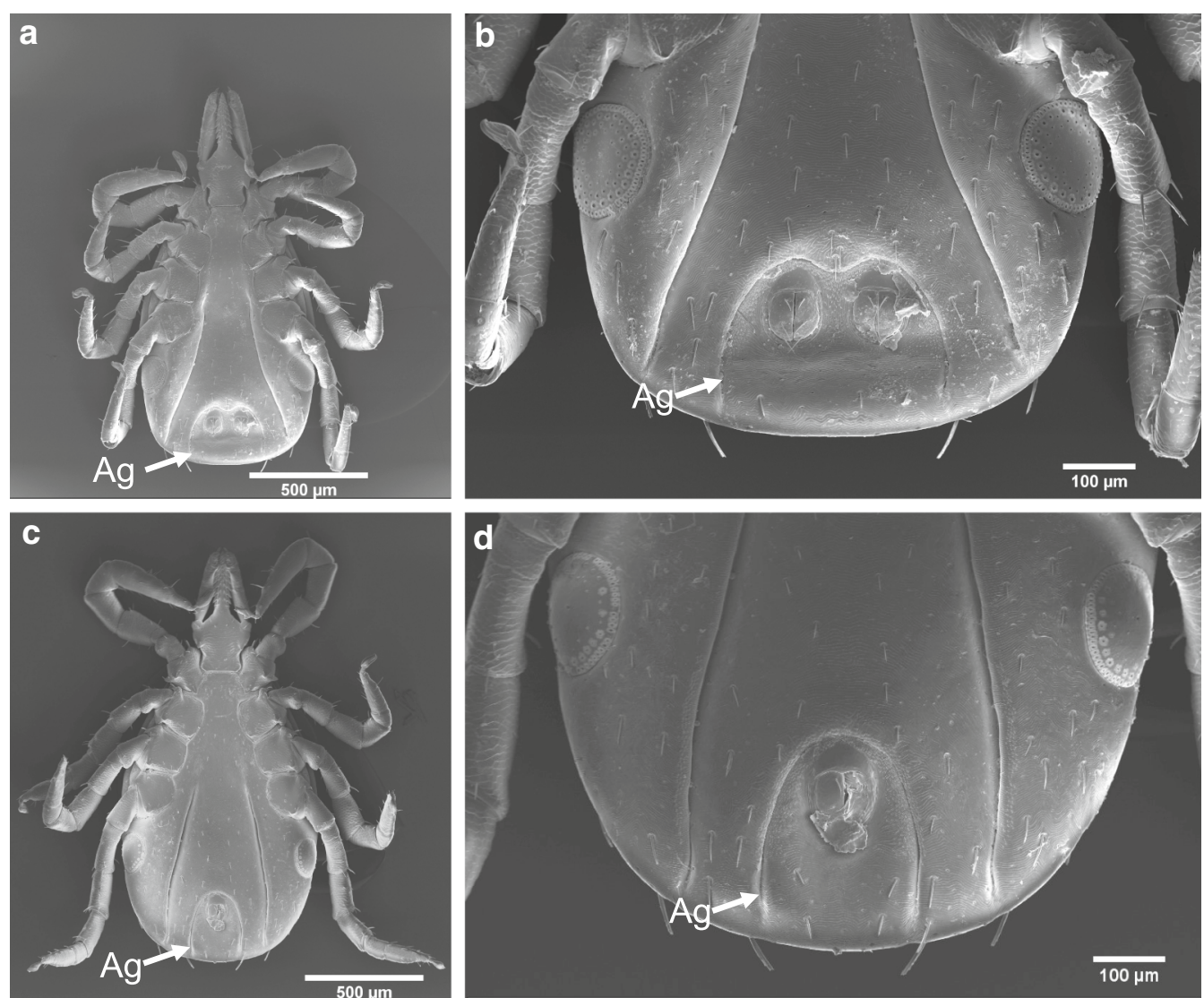

Fig. 1 Scanning electron micrographs of the Ixodes scapularis nymph with two anuses and a normal nymph with a single anus. $\mathbf{a}, \mathbf{b}$ Abnormal tick. Ventral side of whole tick (a) and enlarged portion of the same tick (b) with two anuses. $\mathbf{c}, \mathbf{d}$ Normal tick. Ventral side of whole tick (c) and enlarged portion of the same tick (d) with one anus. Scale bar: a, c $500 \mu \mathrm{m}, \mathbf{b}, \mathbf{d} 100 \mu \mathrm{m}$. Ag Anal groove

pore in the normal nymph tick was $75-77 \mu \mathrm{m}$ in diameter and the anal grove was apporximately $210 \mu \mathrm{m}$ wide.

In a recent study, we developed a novel method for the generation of Anaplasma phagocytophiluminfected ticks via microinjection [19]. Microinjection is a routine technique to introduce pathogens, doublestranded RNA, inhibitors, or metabolites into ticks [18, 19]. Two types of microinjections can be performed, one into the anal pore and the other into the body [18, 19]. Microinjections will result in the physical disruption of the body or anus in ticks. However, when properly done, ticks can sustain and survive these two types of microinjections. As we noted two anuses in a nymphal tick, we questioned whether physical disruption of the anus in the tick with the double anuses would have any effect on tick viability. To determine if the tick with double anus can sustain microinjection, we injected $A$. phagocytophilum-dense core form (Ap-DC) into one of the anuses. A $2 \mathrm{~h}$ post-microinjection, ticks were visualized under a stereomicroscope to assess the overall health and fitness. The tick with two anuses appeared to be healthy and mobile (Additional file 1: Video S1).

We have published several studies using I. scapularis ticks obtained from several sources including BEI resources $(\mathrm{CDC})$, the Oklahoma Tick Facility, and the Connecticut Agricultural Experimental Station and Yale School of Public Health (Yale University) [17, 18, 21-26]. Until this finding, we had not observed any tick containing double anus, suggesting a rare abnormality in this group of ticks. To our knowledge, in this study we did not find any other local abnormalities in the double anuscontaining tick.

In a study on Amblyomma variegatum, Latif et al. [27] identified abnormalities in 16 out of 5000 larvae. These authors observed external abnormalities, such as partial twinning of the posterior region of the body with the presence of two anal pores and two genital grooves and also identified the presence of two anal pores in nymphal and adult stages of these ticks. Of the 16 abnormal ticks identified in the study [27], 11 engorged 
successfully on rabbits, suggesting that abnormalities such as presence of two anal pores may not affect tick feeding. The tick with two anuses identified in our study was noted to be viable and mobile even after $2 \mathrm{~h}$ postmicroinjection, suggesting that the presence of this local abnormality may not affect mobility of these ticks. We hypothesize that the two anuses in an unfed nymphal tick identified in our study is presumably related to somatic or germinal mutations that could have occurred during the development from the egg to thelarval stage of this tick. This abnormality might have retained during molting from larval to nymphal stage.

Larson and Paskewitz [13] reported four abnormalities in field-collected I. scapularis ticks, including schizomely of the third leg in the first tick, slight asymmetry and distorted point on the alloscutum in the second tick, ectromely of the third leg on the right side of the third tick, and extreme asymmetry and enlarged coxae in the fourth tick. Prusinski et al. [16] reported gynandromorphism for the first time in I. scapularis. Soghigian et al. [15] reported the first evidence of dwarfism in I. scapularis that was found parasitizing a human host. Our report on the presence of double anus in one unfed nymphal tick further adds to the list of abnormalities observed in I. scapularis. Ixodes scapularis is a medically important vector for several human pathogens $[1,2]$. The findings from the current study and other published studies that reported abnormalities in I. scapularis $[13,15,16]$ provide evidence for further studies to focus on looking at abnormalities in all field-collected ticks.

\section{Conclusions}

This report confirms the rare occurrence of double anus in a laboratory-reared medically important $I$. scapularis tick. Future studies that focus on both pathogen surveillance and looking at abnormalities in field-collected ticks may provide information on whether abnormalities in ticks have any implications in disease transmission and vector competency.

\section{Abbreviations}

DC: Dense core form of Anaplasma phagocytophilum; HL-60: Human leukemia cell line; SEM: Scanning electron microscopy.

\section{Supplementary Information}

The online version contains supplementary material available at https://doi. org/10.1186/s13071-021-04757-8.

Additional file 1: Video S1. Live stereomicroscope ventral view of the abnormal Ixodes scapularis nymph with two anuses (right side) and a normal tick (left side) with a single anus. The scale bar on the right side indicates $1 \mathrm{~mm}$.

\section{Acknowledgements}

We thank Judy Williamson and Terry Smith for their help with SEM images. Microscopy was performed at the VCU Massey Cancer Center Microscopy Core Facility and supported, in part, with funding from NIH-NCI Cancer Center Support Grant P30 CA016059. We thank Dr. Michael Levin for the supply of larvae. The following reagent was provided by Centers for Disease Control and Prevention for distribution by BEI Resources, NIAID, NIH: Ixodes scapularis Larvae (Live), NR-44115.

\section{Authors' contributions}

$V T, F A L$, and GN performed the experiments. VT, $H S$, and GN analyzed the data. $V T, H S$, and GN designed the study. VT and GN wrote the paper. GN supervised overall investigations. All authors read, edited and approved the manuscript.

\section{Funding}

This study was supported by funding from National Institute of Allergy and Infectious Diseases (NIAID), National Institutes of Health (NIH) (Award number: R01Al130116) to GN.

\section{Availability of data and materials}

All data that support the findings reported in this study are included in the main article file and in the supplementary information file.

\section{Declarations}

\section{Ethics approval and consent to participate}

All animal work in this study was carried out in strict accordance with the recommendations in the Guide for the Care and Use of Laboratory Animals of the National Institute of Health $(\mathrm{NIH})$. The Old Dominion University Institutional Animal Care and Use Committee (IACUC, Animal Welfare Assurance Number: A3172-01) protocol 19-009 was used in mice experiments. Acepromazine tranquilizer was administered to the animals before handling to minimize anxiety and/or discomfort, and all efforts were made to minimize suffering.

\section{Consent for publication}

Not applicable.

\section{Competing interests}

The authors have declared that no competing interests exist.

\section{Author details}

'Department of Biological Sciences, Old Dominion University, Norfolk, VA, USA. ${ }^{2}$ Department of Physiological Sciences, Eastern Virginia Medical School Norfolk, VA, USA. ${ }^{3}$ Center for Molecular Medicine, Old Dominion University, Norfolk, VA, USA. ${ }^{4}$ Present Address: Department of Biomedical and Diagnostic Sciences, College of Veterinary Medicine, University of Tennessee, Knoxville, TN 37996, USA

Received: 26 February 2021 Accepted: 29 April 2021

Published online: 11 May 2021

\section{References}

1. Neelakanta G, Sultana H. Transmission-blocking vaccines: focus on anti-vector vaccines against tick-borne diseases. Arch Immunol Ther Exp (Warsz). 2015;63(3):169-79. https://doi.org/10.1007/s00005-014-0324-8.

2. Wikel SK. Ticks and tick-borne infections: complex ecology, agents, and host interactions. Vet Sci. 2018;5(2):60. https://doi.org/10.3390/vetsci5020 060.

3. Anderson JF, Magnarelli LA. Biology of ticks. Infect Dis Clin North Am. 2008;22(2):195-215. https://doi.org/10.1016/j.idc.2007.12.006.

4. Neumann LG. Anomalie d'ixodide's. Arch Parasitol. 1899;2:463-5 (in French).

5. Buczek A, Bartosik K, Kuczynski P. Evaluation of the effect of various concentrations of selected pyrethroids on the development of Dermacentor reticulatus eggs and larvae. Ann Agric Environ Med. 2013;20(3):447-51.

6. Campana-Rouget Y. Teratology of ticks. Ann Parasitol Hum Comp. 1959;34(3):209-60, 354-430. 
7. Ogden NH, Mechai S, Margos G. Changing geographic ranges of ticks and tick-borne pathogens: drivers, mechanisms and consequences for pathogen diversity. Front Cell Infect Microbiol. 2013;3:46. https://doi.org/ 10.3389/fcimb.2013.00046.

8. Ostfeld RS, Canham CD, Oggenfuss K, Winchcombe RJ, Keesing F. Climate, deer, rodents, and acorns as determinants of variation in lyme-disease risk. PLoS Biol. 2006;4(6):e145. https://doi.org/10.1371/journal.pbio.00401 45.

9. Schulze TL, Jordan RA, Schulze CJ, Hung RW. Precipitation and temperature as predictors of the local abundance of Ixodes scapularis (Acari: |xodidae) nymphs. J Med Entomol. 2009;46(5):1025-9. https://doi.org/10. 1603/033.046.0508.

10. Siuda K. Investigations on the biology of the tick Argas (Agras) polonicus Siuda, Hoogstraal, Clifford et Wassef, 1979 ((Acarina: Ixodides: Argasidae). 3. Effect of temperature and relative humidity on embryonic development and egg hatch. Folia Biol (Krakow). 1981;29(1):9-39.

11. Nowak-Chmura M. Teratological changes in tick morphology in ticks feeding on exotic reptiles. J Nat His. 2012;46(15-16):911-21. https://doi. org/10.1080/00222933.2011.651635.

12. Kar S, Akyildiz G, Yilmazer N, Shaibi T, Gargili A, Vatansever Z. External morphological anomalies in ixodid ticks from Thrace. Turkey Exp Appl Acarol. 2015;67(3):457-66. https://doi.org/10.1007/s10493-015-9948-6.

13. Larson SR, Paskewitz SM. Teratological Nymphal /xodes scapularis (Acari: Ixodidae) from Wisconsin. J Med Entomol. 2016;53(2):477-9. https://doi. org/10.1093/jme/tjv198

14. Tovornik D. Teratological forms of Ixodid ticks. Bioloski Vestnik. 1987;35:91-100.

15. Soghigian J, Ridge GE, Stafford KC 3rd, Molaei G. The first evidence of Nanism in /xodes (Ixodes) scapularis (Acari: Ixodidae), found parasitizing a human host. J Med Entomol. 2017;54(5):1224-8. https://doi.org/10.1093/ jme/tjx111.

16. Prusinski MA, Mertins JW, Meehan LJ. Two gynandromorphs of /xodes scapularis (Acari: Ixodidae) from New York State. J Med Entomol. 2015;52(2):278-82. https://doi.org/10.1093/jme/tjv009.

17. Ramasamy E, Taank V, Anderson JF, Sultana H, Neelakanta G. Repression of tick microRNA-133 induces organic anion transporting polypeptide expression critical for Anaplasma phagocytophilum survival in the vector and transmission to the vertebrate host. PLoS Genet. 2020;16(7):e1008856. https://doi.org/10.1371/journal.pgen.1008856.

18. Taank V, Dutta S, Dasgupta A, Steeves TK, Fish D, Anderson JF, et al. Human rickettsial pathogen modulates arthropod organic anion transporting polypeptide and tryptophan pathway for its survival in ticks. Sci Rep. 2017;7(1):13256. https://doi.org/10.1038/s41598-017-13559-x.

19. Taank V, Ramasamy E, Sultana H, Neelakanta G. An efficient microinjection method to generate human anaplasmosis agent Anaplasma phagocytophilum-infected ticks. Sci Rep. 2020;10(1):15994. https://doi.org/10.1038/ s41598-020-73061-9.

20. Carlyon JA. Laboratory maintenance of Anaplasma phagocytophilum. Curr Protoc Microbiol. 2005;Chapter 3:Unit 3A.2. https://doi.org/10.1002/ 9780471729259.mc03a02s00.

21. Khanal S, Taank V, Anderson JF, Sultana H, Neelakanta G. Arthropod transcriptional activator protein-1 (AP-1) aids tick-rickettsial pathogen survival in the cold. Sci Rep. 2018;8(1):11409. https://doi.org/10.1038/ s41598-018-29654-6.

22. Sultana H, Neelakanta G, Kantor FS, Malawista SE, Fish D, Montgomery RR, et al. Anaplasma phagocytophilum induces actin phosphorylation to selectively regulate gene transcription in /xodes scapularis ticks. J Exp Med. 2010;207(8):1727-43. https://doi.org/10.1084/jem.20100276.

23. Turck JW, Taank V, Neelakanta G, Sultana H. Ixodes scapularis Src tyrosine kinase facilitates Anaplasma phagocytophilum survival in its arthropod vector. Ticks Tick Borne Dis. 2019;10(4):838-47. https://doi.org/10.1016/j. ttbdis.2019.04.002.

24. Vora A, Taank V, Dutta SM, Anderson JF, Fish D, Sonenshine DE, et al. Ticks elicit variable fibrinogenolytic activities upon feeding on hosts with different immune backgrounds. Sci Rep. 2017;7:44593. https://doi.org/10. 1038/srep44593.

25. Dahmani M, Anderson JF, Sultana H, Neelakanta G. Rickettsial pathogen uses arthropod tryptophan pathway metabolites to evade reactive oxygen species in tick cells. Cell Microbiol. 2020;22(10):e13237. https:// doi.org/10.1111/cmi.13237.

26. Neelakanta G, Sultana H, Fish D, Anderson JF, Fikrig E. Anaplasma phagocytophilum induces /xodes scapularis ticks to express an antifreeze glycoprotein gene that enhances their survival in the cold. J Clin Invest. 2010;120(9):3179-90. https://doi.org/10.1172/JCl42868.

27. Latif AA, Dhadialla TS, Newson RM. Abnormal development of Amblyomma variegatum (Acarina: Ixodidae). J Med Entomol. 1988;25(2):142-3. https://doi.org/10.1093/jmedent/25.2.142.

\section{Publisher's Note}

Springer Nature remains neutral with regard to jurisdictional claims in published maps and institutional affiliations.
Ready to submit your research? Choose BMC and benefit from:

- fast, convenient online submission

- thorough peer review by experienced researchers in your field

- rapid publication on acceptance

- support for research data, including large and complex data types

- gold Open Access which fosters wider collaboration and increased citations

- maximum visibility for your research: over 100M website views per year

At BMC, research is always in progress.

Learn more biomedcentral.com/submissions 